\title{
Investigation of effective potential of electron-ion interaction in semibounded metal
}

\author{
Markovych B. \\ Lviv Polytechnic National University, \\ 12 S. Bandera Str., Lviv, 79013, Ukraine
}

(Received 30 November 2018)

\begin{abstract}
The effective potential of the electron-ion interaction in a semibounded metal (potassium) is calculated numerically, taking into account the local field correction in the Hubbard form, using the local pseudopotential of Krasko-Gursky. The influence of the metal/vacuum interface and the approximation for the local field correction on the behavior of the effective potential of the electron-ion interaction is investigated.
\end{abstract}

Keywords: effective electron-ion interaction, semibounded metal, local field correction. 2000 MSC: $82 B 24$

UDC: 530.145

DOI: $10.23939 / \mathrm{mmc} 2018.02 .184$

\section{Introduction}

The development of modern technology poses the task of obtaining materials with prediction of their properties, the construction of devices whose essential features are strong spatial heterogeneity and macroscopic manifestation of quantum effects. Despite the significant progress in the condensed matter physics, in fact, a microscopic theory of inhomogeneous systems remains at the initial stage of its development. The scale of heterogeneity can range from atomic to macroscopic. The atomic structure of a substance causes a quantum-mechanic and statistical description of inhomogeneous condensed systems as the most detailed and exhaustive. For condensed systems, we can obtain information on the nature of interatomic interactions and the motion of atoms, using the conclusions of the many-electron theory. Such a state of the theory of inhomogeneous metal systems is due to a set of requirements that must satisfy the theory of inhomogeneous many-electron systems. The main requirements for the microscopic theory are the need to simultaneously take into account the self-consistent effects for electron and ion subsystems, dielectric screening, effects of exchange and correlation in an inhomogeneous electron gas, effects of discreteness of ion subsystem, effects of pair and higher interactions and correlations in an inhomogeneous ion subsystem.

In Refs. [1,2], an attempt is made to construct a self-consistent many-particle microscopic theory of non-uniform metal systems that would take into account equally the electron and ion subsystems. In the framework of this theory, general expressions for a thermodynamic potential and many-particle distribution functions of electrons in semibounded metal are obtained. This expressions are expansions in degrees of a "difference potential" (the difference between a nonlocal pseudopotential and the Coulomb potential of interaction between electron and a positive charge of a semi-infinite jellium model) taking into account dielectric screening, effects of exchange and correlation in a inhomogeneous electronic subsystem. In the case of a local pseudopotential, this theory is in agreement with Ref. [3]. In the presented paper, the effective potential of the electron-ion interaction in the semibounded metal (potassium) is calculated, the effect of the local field correction and the metal/vacuum interface are investigated. 


\section{Model}

We consider a semibounded metal, ions of which have charges $\mathcal{Z} e$ and Cartesian coordinates $\mathbf{R}_{j}=\left(X_{j}, Y_{j}, Z_{j}\right)$, where $-\infty<X_{j}, Y_{j}<+\infty,-\infty<Z_{j} \leqslant 0, z=0$ is the plane equation of the metal/vacuum interface, $j=1, \ldots, N_{\text {ion }}$. Electrons of a semibounded metal have coordinates $\mathbf{r}_{i}$, $i=1, \ldots, N$. A Hamiltonian of this model can be written as

$$
H=-\frac{\hbar^{2}}{2 m} \sum_{i=1}^{N} \Delta_{i}+\frac{1}{2} \sum_{i \neq j=1}^{N} \frac{e^{2}}{\left|\mathbf{r}_{i}-\mathbf{r}_{j}\right|}+\sum_{j=1}^{N_{\text {ion }}} \frac{\mathbf{P}_{j}^{2}}{2 M}+\frac{1}{2} \sum_{i \neq j=1}^{N_{\text {ion }}} \frac{(\mathcal{Z} e)^{2}}{\left|\mathbf{R}_{i}-\mathbf{R}_{j}\right|}+\sum_{i=1}^{N} \sum_{j=1}^{N_{\text {ion }}} w\left(\mathbf{r}_{i}, \mathbf{R}_{j}\right),
$$

where the first term is the kinetic energy of electrons, the second term is the potential energy of the Coulomb interaction between electrons, the third term is the kinetic energy of ions ( $\mathbf{P}$ is the operator of ion impulse), the fourth term is the potential energy of the ion-ion interaction and the last term is the energy of electron-ion interaction. We assume that the system is electroneutral, i.e.

$$
\mathcal{Z} N_{\text {ion }}=N
$$

We present the potential of electron-ion interaction as:

$$
w\left(\mathbf{r}_{i}, \mathbf{R}_{j}\right)=w\left(\left|\mathbf{r}_{i}-\mathbf{R}_{j}\right|\right)+\Delta w\left(\mathbf{r}_{i}, \mathbf{R}_{j}\right)
$$

where $w\left(\left|\mathbf{r}_{i}-\mathbf{R}_{j}\right|\right)$ is a potential of the electron-ion interaction in the case of unbounded metal (pseudopotential, $\Delta w\left(\mathbf{r}_{i}, \mathbf{R}_{j}\right)$ is the deviation of the potential of the electron-ion interaction in the semibounded metal from the one $w\left(\left|\mathbf{r}_{i}-\mathbf{R}_{j}\right|\right)$.

We extract from the Hamiltonian (1) a Hamiltonian of the semi-infinite jellium model $H_{\text {jell }}$ [46], which is used as a basic system for the study of thermodynamic and structural properties of semibounded metal. As a result, we get that

$$
H=H_{\text {jell }}+\delta H_{\mathrm{ii}}+\sum_{i=1}^{N} \sum_{j=1}^{N_{\text {ion }}} \delta w\left(\left|\mathbf{r}_{i}-\mathbf{R}_{j}\right|\right)
$$

where

$$
\begin{gathered}
\delta H_{\text {ii }}=\sum_{j=1}^{N_{\text {ion }}} \frac{\mathbf{P}_{j}^{2}}{2 M}+\frac{1}{2} \sum_{i \neq j=1}^{N_{\text {ion }}} \frac{(\mathcal{Z} e)^{2}}{\left|\mathbf{R}_{i}-\mathbf{R}_{j}\right|}-\frac{1}{2} \int \mathrm{d} \mathbf{R} \int \mathrm{d} \mathbf{R}^{\prime} \frac{\varrho_{+}(\mathbf{R}) \varrho_{+}\left(\mathbf{R}^{\prime}\right)}{\left|\mathbf{R}-\mathbf{R}^{\prime}\right|} \\
H_{\text {jell }}=H_{\text {jell }}^{\text {unif }}+\sum_{i=1}^{N} V_{\text {surf }}\left(\mathbf{r}_{i}\right)+\frac{1}{2} \int \mathrm{d} \mathbf{R} \int \mathrm{d} \mathbf{R}^{\prime} \frac{\varrho_{+}(\mathbf{R}) \varrho_{+}\left(\mathbf{R}^{\prime}\right)-(e N / V)^{2}}{\left|\mathbf{R}-\mathbf{R}^{\prime}\right|} \\
V_{\text {surf }}\left(\mathbf{r}_{i}\right)=V_{\text {jell }}\left(\mathbf{r}_{i}\right)+V_{\text {ion }}\left(\mathbf{r}_{i}\right)
\end{gathered}
$$

is a surface potential acting on electrons,

$$
\delta w\left(\left|\mathbf{r}_{i}-\mathbf{R}_{j}\right|\right)=w\left(\left|\mathbf{r}_{i}-\mathbf{R}_{j}\right|\right)+\frac{1}{N_{\text {ion }}} \int \mathrm{d} \mathbf{R} \frac{e \varrho+(\mathbf{R})}{\left|\mathbf{r}_{i}-\mathbf{R}\right|}
$$

is a "difference potential",

$$
H_{\text {jell }}^{\text {unif }}=-\frac{\hbar^{2}}{2 m} \sum_{i=1}^{N} \Delta_{i}+\frac{1}{2} \sum_{i \neq j=1}^{N} \frac{e^{2}}{\left|\mathbf{r}_{i}-\mathbf{r}_{j}\right|}-\frac{e^{2} N}{V} \sum_{i=1}^{N} \int \mathrm{d} \mathbf{R} \frac{1}{\left|\mathbf{r}_{i}-\mathbf{R}\right|}+\frac{(e N)^{2}}{2 V^{2}} \int \mathrm{d} \mathbf{R} \int \mathrm{d} \mathbf{R}^{\prime} \frac{1}{\left|\mathbf{R}-\mathbf{R}^{\prime}\right|}
$$

is the Hamiltonian of the homogeneous jellium, $V=S L$ is the volume of the system, $S$ is the surface area of semibounded metal, $L$ determines the domain of the change of the electron coordinate, which 
is normal to the interface: $z \in(-L / 2,+L / 2), S \rightarrow \infty, L \rightarrow \infty$.

$$
V_{\text {jell }}\left(\mathbf{r}_{i}\right)=e \int \mathrm{d} \mathbf{R} \frac{e N / V-\varrho_{+}(\mathbf{R})}{\left|\mathbf{r}_{i}-\mathbf{R}\right|}
$$

is the part of the surface potential, which is formed semi-infinite jellium.

$$
V_{\text {ion }}\left(\mathbf{r}_{i}\right)=\sum_{j=1}^{N_{\text {ion }}} \Delta w\left(\mathbf{r}_{i}, \mathbf{R}_{j}\right)
$$

is the part of the surface potential created by the deviation $\Delta w\left(\mathbf{r}_{i}, \mathbf{R}_{j}\right)$ of the true potential of the electron-ion interaction in the semibounded metal $w\left(\mathbf{r}_{i}, \mathbf{R}_{j}\right)$ from the periodic potential $w\left(\left|\mathbf{r}_{i}-\mathbf{R}_{j}\right|\right)$.

$$
\rho_{+}(\mathbf{R}) \equiv \varrho_{+}(Z)=\varrho_{0} \theta(-Z), \quad \varrho_{0}=\frac{e N}{V / 2}
$$

is a distribution of the ion density within the semi-infinite jellium model.

In the following, we assume that the potential of the electron-ion interaction $w\left(\left|\mathbf{r}_{i}-\mathbf{R}_{j}\right|\right)$ can be modeled by a nonlocal model pseudopotential [7-10]

$$
w\left(\left|\mathbf{r}_{i}-\mathbf{R}_{j}\right|\right)=-\frac{\mathcal{Z} e^{2}}{\left|\mathbf{r}_{i}-\mathbf{R}_{j}\right|}+\sum_{l^{\prime}=0}^{l} f_{l^{\prime}}\left(\left|\mathbf{r}_{i}-\mathbf{R}_{j}\right|\right) \mathrm{P}_{l^{\prime}},
$$

where

$$
\mathrm{P}_{l}=\sum_{m=-l}^{l}\left|\mathrm{Y}_{l, m}\right\rangle\left\langle\mathrm{Y}_{l, m}\left|\equiv \sum_{m=-l}^{l}\right| l, m\right\rangle\langle l, m|
$$

is projection operator, $\mathrm{Y}_{l, m}$ is the spherical function [11], and

$$
\sum_{l} \mathrm{P}_{l}=1
$$

integers $l$ and $m$ are orbital and magnetic quantum numbers of electron, respectively The concrete expressions of the functions $f_{l}\left(\left|\mathbf{r}_{i}-\mathbf{R}_{j}\right|\right)$ depend on the choice of the pseudopotential model.

\section{Effective potential of electron-ion interaction}

The electron-ion interaction in the metal due to the screening by the electron subsystem differs from one, which is described by a nonlocal model pseudopotential (3). According to Ref. [1], the effective potential of electron-ion interaction has the form

$$
w^{\text {eff }}\left(r_{\|}, z_{1}, Z_{2}\right)=\frac{1}{2 \pi} \int_{0}^{\infty} \mathrm{d} q q \mathrm{~J}_{0}\left(q r_{\|}\right) w^{\text {eff }}\left(q, z_{1}, Z_{2}\right)
$$

where $r_{\|}$is the distance between an electron and an ion in the interface metal/vacuum, $\mathrm{J}_{0}\left(q r_{\|}\right)$is the cylindrical Bessel function of zero order, $w^{\text {eff }}\left(q, z_{1}, Z_{2}\right)$ is a two-dimensional Fourier-image of the effective potential of electron-ion interaction,

$$
w^{\text {eff }}\left(q, z_{1}, Z_{2}\right)=w\left(q, Z_{1}-z_{2}\right)+\frac{\beta}{S L^{2}} \int_{-\infty}^{+\infty} \mathrm{d} z \int_{-\infty}^{+\infty} \mathrm{d} z^{\prime} \nu\left(q, z_{1}-z\right) \overline{\mathfrak{M}}\left(q, z, z^{\prime}\right) w\left(q, z^{\prime}-Z_{2}\right) .
$$


Here $\beta$ is the inverse thermodynamic temperature, $\nu(q, z)=\frac{2 \pi e^{2}}{q} \mathrm{e}^{-q|z|}$ is the two-dimensional Fourierimage of the Coulomb potential, $w\left(q, Z_{1}-z_{2}\right)$ is a two-dimensional Fourier-image of a pseudopotential, $\overline{\mathfrak{M}}\left(q, z, z^{\prime}\right)$ is two-particle correlation function of electrons, which is the solution of such an integral equation [12]:

$$
\overline{\mathfrak{M}}\left(q, z_{1}, z_{2}\right)=\mathfrak{M}^{0}\left(q, z_{1}, z_{2}\right)+\frac{\beta}{S L^{2}} \int_{-\infty}^{+\infty} \mathrm{d} z \int_{-\infty}^{+\infty} \mathrm{d} z^{\prime} \mathfrak{M}^{0}\left(q, z_{1}, z\right)\left[\nu\left(q, z-z^{\prime}\right)-\bar{\nu}\left(q, z-z^{\prime}\right)\right] \overline{\mathfrak{M}}\left(q, z^{\prime}, z_{2}\right)
$$

where $\mathfrak{M}^{0}\left(q, z_{1}, z_{2}\right)$ is two-particle correlation function of electrons without taking into account the Coulomb interaction between them, $\bar{\nu}\left(q, z-z^{\prime}\right)=\frac{1}{L} \sum_{k} \mathrm{e}^{\mathrm{i} k\left(z-z^{\prime}\right)} \bar{\nu}_{k}(q), \bar{\nu}_{k}(q)=\mathcal{G}_{k}(q) \nu_{k}(q)$, $\nu_{k}(q)=\frac{4 \pi e^{2}}{q^{2}+k^{2}}$ is the three-dimensional Fourier-image of the Coulomb potential, $\mathcal{G}_{k}(q)$ is the threedimensional Fourier-image of a local field correction.

\section{Results of numerical calculations and discussion}

Further numerical calculations of the effective potential of the electron-ion interaction are made for potassium $\left(r_{\mathrm{s}}=4.86 a_{\mathrm{B}}\right)$ at the low temperatures, using the local pseudopotential of Krasko-Gursky [9, $10]$,

$$
w(r)=-\frac{\mathcal{Z} e^{2}}{r}+\frac{\mathcal{Z} e^{2}}{r}\left(1+\frac{r a}{r_{\mathrm{c}}}\right) \mathrm{e}^{-\frac{r}{r_{\mathrm{c}}}}
$$

with the following parameters for potassium $[9,10]$ :

$$
\mathcal{Z}=1, \quad a=2.671, \quad r_{\mathrm{c}}=0.689 a_{\mathrm{B}}
$$

Two-dimensional Fourier-image of the pseudopotential of Krasko-Gursky has the form

$$
w(q, z)=-\frac{2 \pi \mathcal{Z} e^{2}}{q} \mathrm{e}^{-q|z|}+2 \pi \mathcal{Z} e^{2}\left[\frac{a|z|}{1+\left(q r_{\mathrm{c}}\right)^{2}}+r_{\mathrm{c}} \frac{1+a+\left(q r_{\mathrm{c}}\right)^{2}}{\left(1+\left(q r_{\mathrm{c}}\right)^{2}\right)^{3 / 2}}\right] \mathrm{e}^{-\sqrt{1+\left(q r_{\mathrm{c}}\right)^{2}} \frac{|z|}{r_{\mathrm{c}}}} .
$$

The surface potential $V_{\text {surf }}$ is modeled by the infinite potential barrier

$$
V_{\text {surf }}(z)=\left\{\begin{array}{cc}
\infty, & z>d \\
0, & z<d
\end{array}\right.
$$

and the local field correction is taken in the Hubbard form for the homogeneous electron gas $[13,14]$

$$
\mathcal{G}_{k}(q)=\frac{1}{2} \frac{q^{2}+k^{2}}{q^{2}+k^{2}+\xi \mathcal{K}_{\mathrm{F}}^{2}},
$$

a two-dimensional Fourier-image of which has the form

$$
\bar{\nu}\left(q, z-z^{\prime}\right)=\frac{\pi e^{2}}{\sqrt{q^{2}+\xi \mathcal{K}_{\mathrm{F}}^{2}}} \mathrm{e}^{-\sqrt{q^{2}+\xi \mathcal{K}_{\mathrm{F}}^{2}}\left|z-z^{\prime}\right|},
$$

where $\mathcal{K}_{\mathrm{F}}=\sqrt{2 m \mu} / \hbar, \mu$ is a chemical potential.

Numerical calculations are performed for the following cases:

1) without taking into account the local field correction $(\bar{\nu}=0)$ in the integral equation (5);

2) taking into account the local field correction in the integral equation (5) in the Hubbard form (8) with the following values of $\xi$ :

- $\xi=1$ (the Hubbard approximation); 
- $\xi=2$ (the Geldard and Vosko approximation);

- $\xi=1+2 /\left(\pi \mathcal{K}_{\mathrm{F}} a_{\mathrm{B}}\right)$ (the Animalu approximation);

- $\xi=1+4 /\left(\pi \mathcal{K}_{\mathrm{F}} a_{\mathrm{B}}\right)$ (the Sham approximation).

In Fig. 1, the dependence of the effective potential of the electron-ion interaction on the distance between electron and ion in the metal/vacuum interface is presented, the electron and ion coordinates, which are normal to the metal/vacuum interface, are fixed and coincident. In the depth of the semibounded metal (see Fig. 1a), there is observed a potential well, the depth of which depends on the chosen approximation for the local field correction. If electron and ion approach the metal/vacuum interface, the depth of the potential well decreases (see Fig. $1 a-1 f$ ).

The Hubbard approximation, as in the theory of homogeneous metal, causes the deepest potential well, and the Sham approximation - the smallest, the rest of the considered approximations provide the intermediate values of the depth of the potential well. Taking into account the local field correction leads to a significant deepening of the potential well, than is in the case of the random phase approximation.

In Fig. 2, the dependence of the effective potential of the electron-ion interaction from the electron coordinate, which is the normal to the metal/vacuum interface, the ion coordinate is fixed, the distance between electron and ion in the metal/vacuum interface is zero. In the depth of the metal (see Fig. $2 a$ ), the potential wells on the left and right are symmetric; there is no influence of the metal/vacuum interface at such distances. If ion approaches the metal/vacuum interface, the potential well on the right decreases (see Fig. $2 c-2 f$ ).

Figs. 1,2 show that the effective potential of the electron-ion interaction is less sensitive to the choice of approximation for the local field correction than the effective potentials of the electronelectron interaction [15] and the ion-ion interaction [12]. This is due to the fact that the induced interaction between electron and ion is insignificant compared to direct electron-ion interaction.

In Fig. 3 the dependence of the effective potential of the electron-ion interaction on the distance between electron and ion in the metal/vacuum interface and the electron coordinate, which is the normal to this interface is given, while position of ion is fixed. Numerical calculations are performed for $\xi=1$ (the Hubbard approximation). In Fig. $3 a$, the effective potential of the electron-ion interaction is shown when ion is deeply in the semibounded metal, i.e. in the absence of the influence of the metal/vacuum interface. From this figure it is clear that the effective potential of the electron-ion interaction is axially symmetric. The same is clearly seen from Figs. $1 a, 2 a$. The breaking of axial symmetry with the approach of ion to the metal/vacuum interface is clearly seen from Fig. $3 c-3 f$. If ion approaches the metal/vacuum interface, the potential well on the right decreases, the induced electron-ion interaction decreases as a result of a decrease of the electron concentration near the metal/vacuum interface.

From Figs. 1-3 it is evident that if electron and ion approach from the depth of the semibounded metal to the metal/vacuum interface, the screening effects decrease as a result of a decrease in the electron concentration. If electron and ion move from the metal/vacuum interface to the vacuum, the effective potential of the electron-ion interaction tends to the potential of electron-ion interaction

$$
\lim _{z_{1}, Z_{2} \rightarrow \infty} w^{\mathrm{eff}}\left(r_{\|}, z_{1}, Z_{2}\right)=w\left(r_{\|}, z_{1}-Z_{2}\right),
$$

i.e. the integral term in Eq. (4) disappears because the two-particle correlation function of the electrons $\overline{\mathfrak{M}}\left(q, z, z^{\prime}\right)$ tends to zero with moving of the electrons to the vacuum.

[1] Vavrukh M. V., Kostrobij P. P., Markovych B. M. Bazisnij pidhid v teoriï bagatoelektronnih sistem. Rastr7, Lviv (2017), (in Ukrainian).

[2] Kostrobij P. P., Markovych B. M. Semi-infinite metal: perturbative treatment based on semi-infinite jellium. Condensed Matter Physics. 11 (4), 641-651 (2008). 

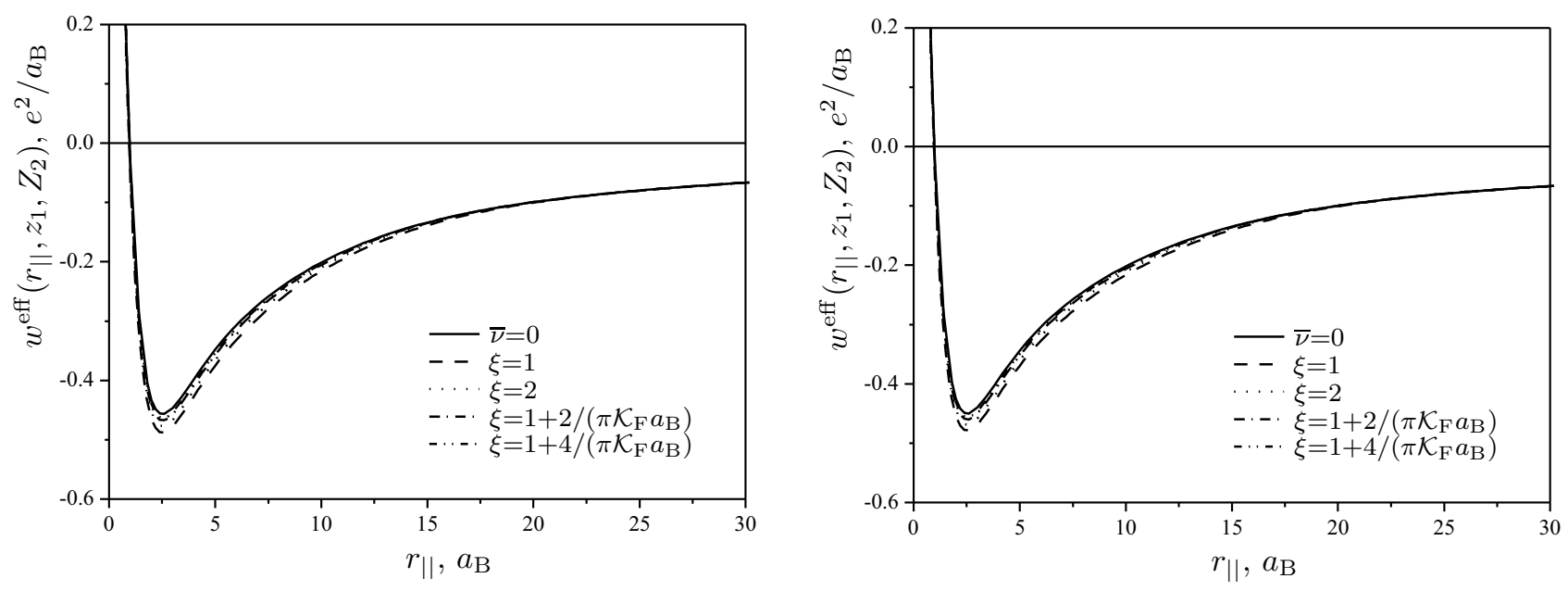

$\boldsymbol{a}\left(z_{1}=Z_{2}=-30 a_{\mathrm{B}}\right)$

$$
\boldsymbol{b}\left(z_{1}=Z_{2}=-10 a_{\mathrm{B}}\right)
$$
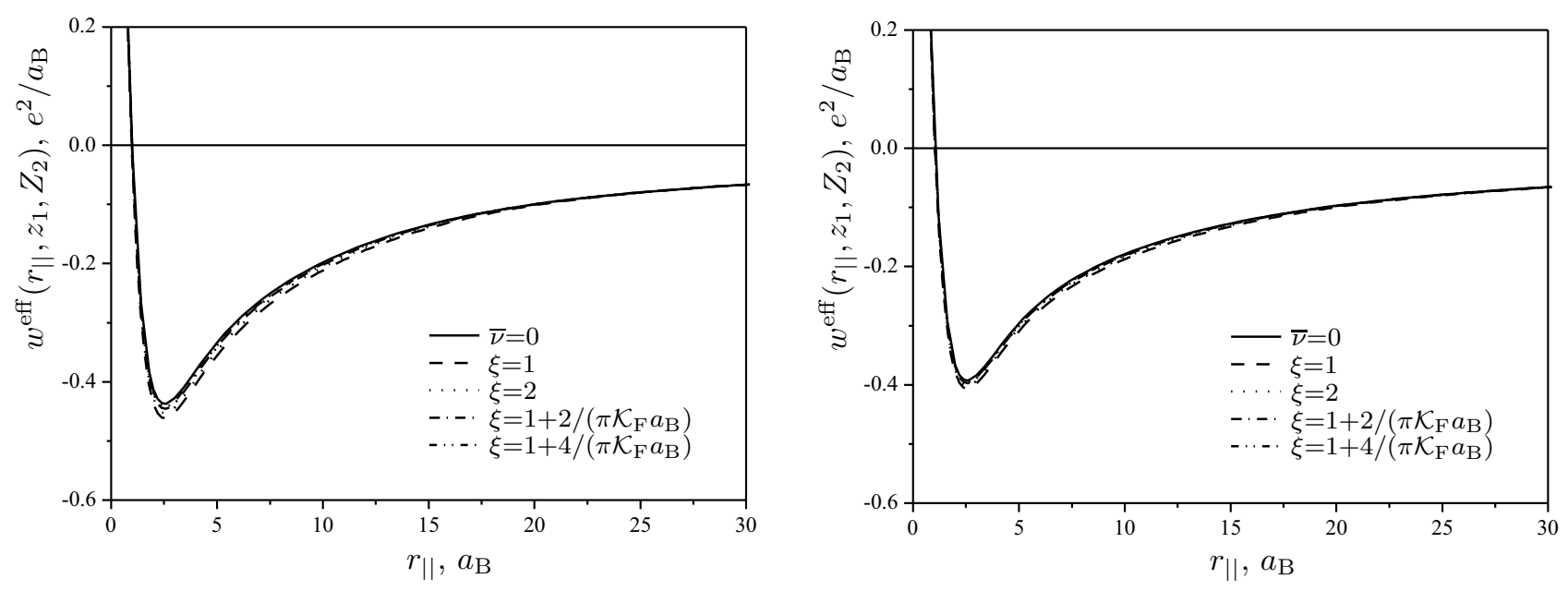

$\boldsymbol{c}\left(z_{1}=Z_{2}=-8 a_{\mathrm{B}}\right)$

$\boldsymbol{d}\left(z_{1}=Z_{2}=-4 a_{\mathrm{B}}\right)$
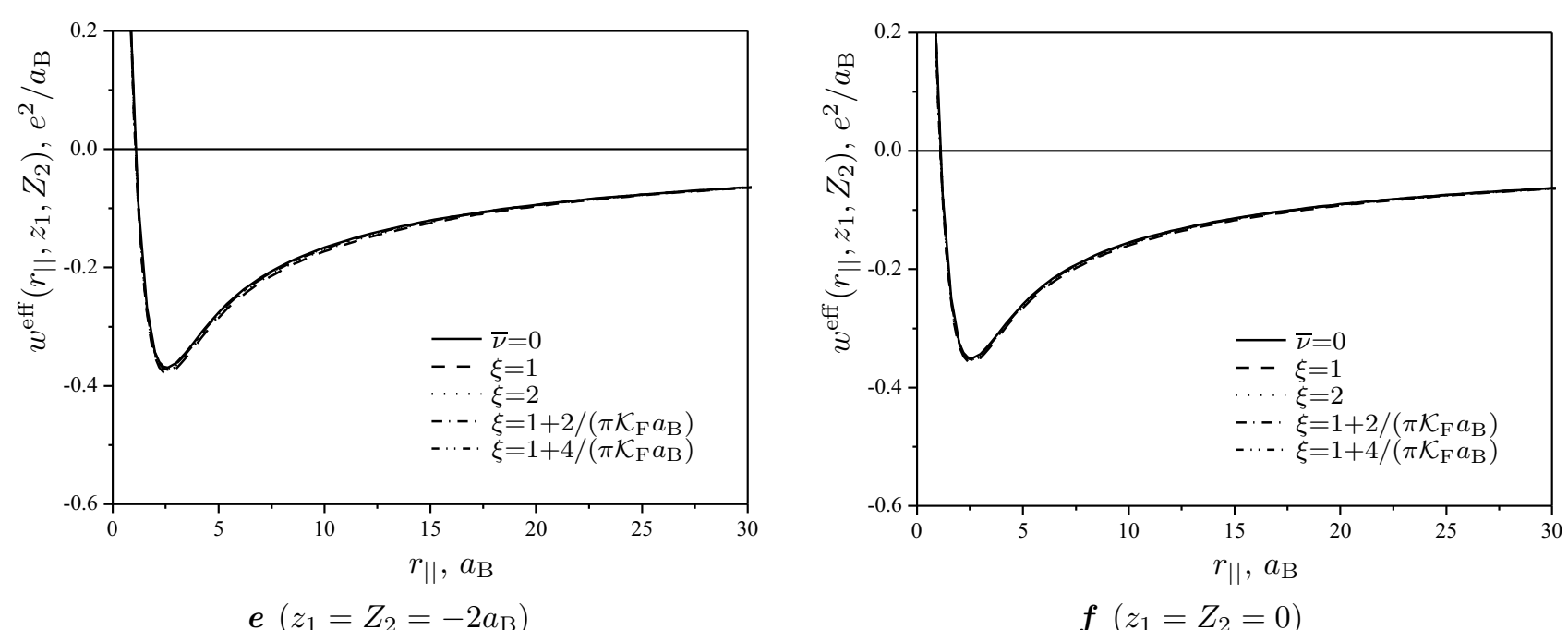

Fig. 1. The effective potential of the electron-ion interaction as a function of the distance between electron and ion in the parallel plane to the metal/vacuum interface. 


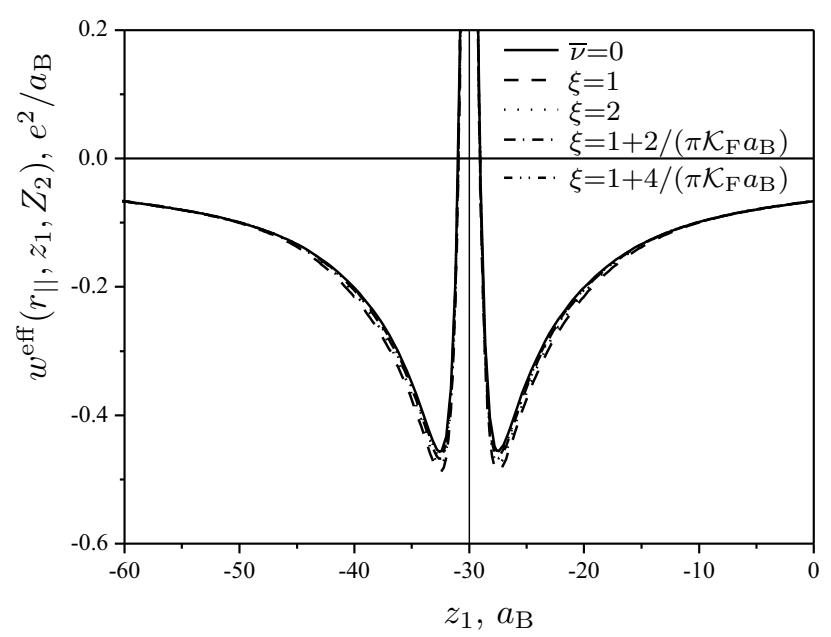

$\boldsymbol{a}\left(r_{\|}=0, Z_{2}=-30 a_{\mathrm{B}}\right)$

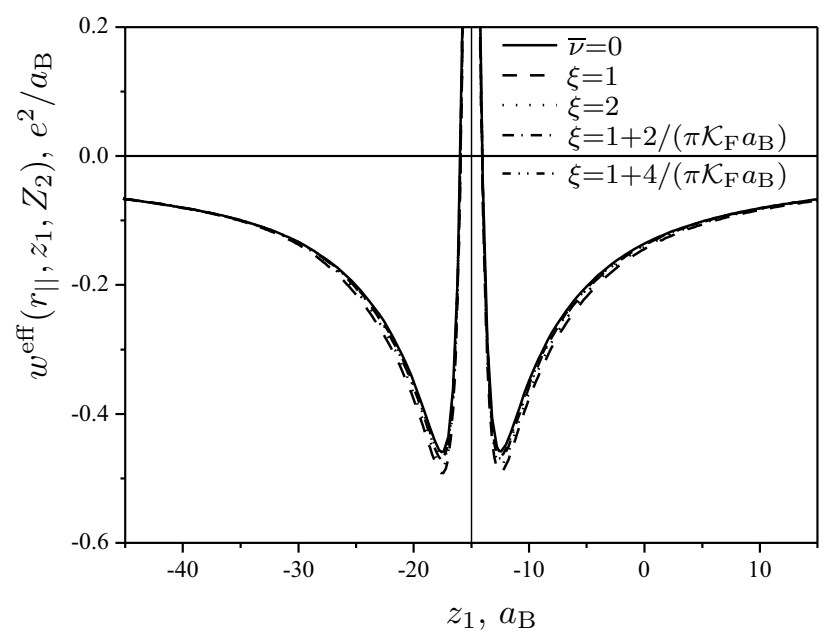

$c\left(r_{\|}=0, Z_{2}=-15 a_{\mathrm{B}}\right)$

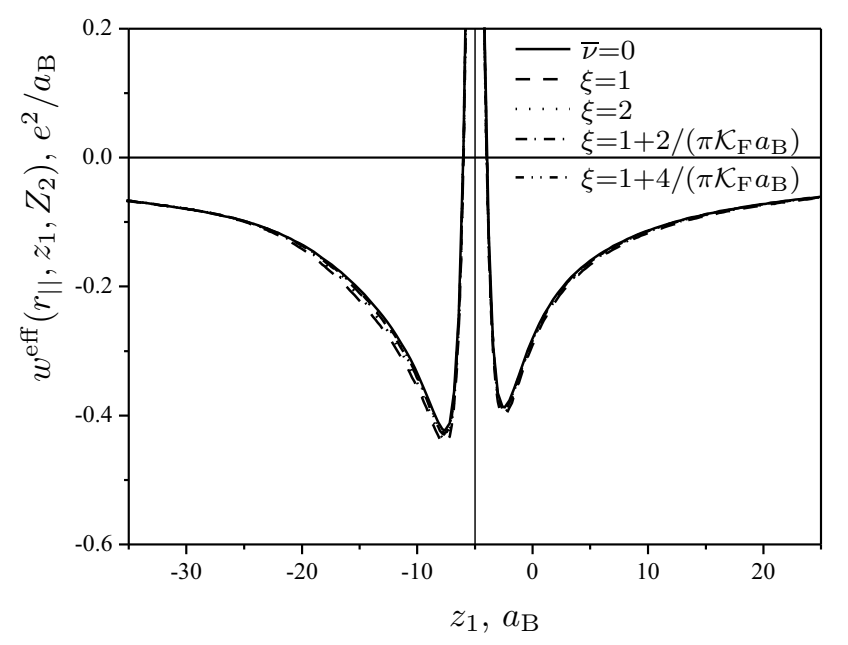

$e\left(r_{\|}=0, Z_{2}=-5 a_{\mathrm{B}}\right)$

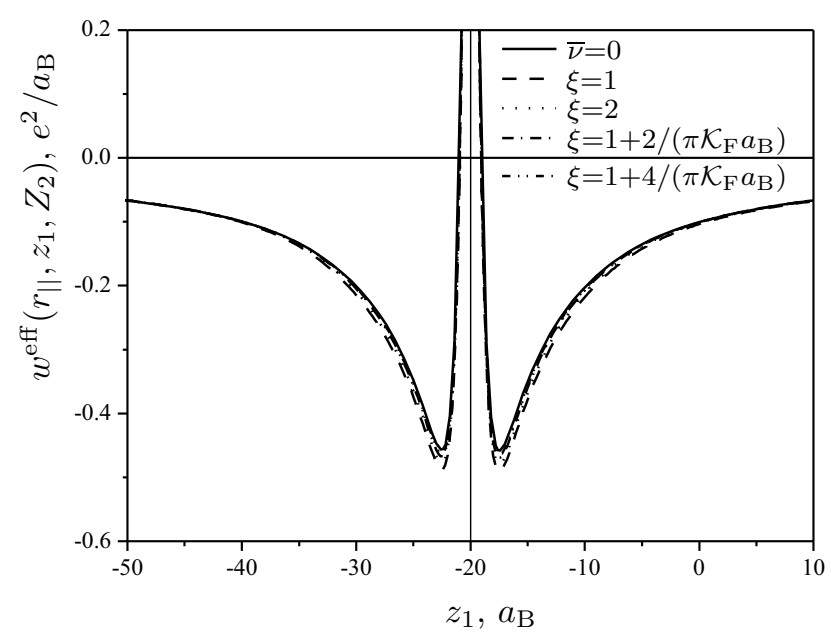

$\boldsymbol{b}\left(r_{\|}=0, Z_{2}=-20 a_{\mathrm{B}}\right)$

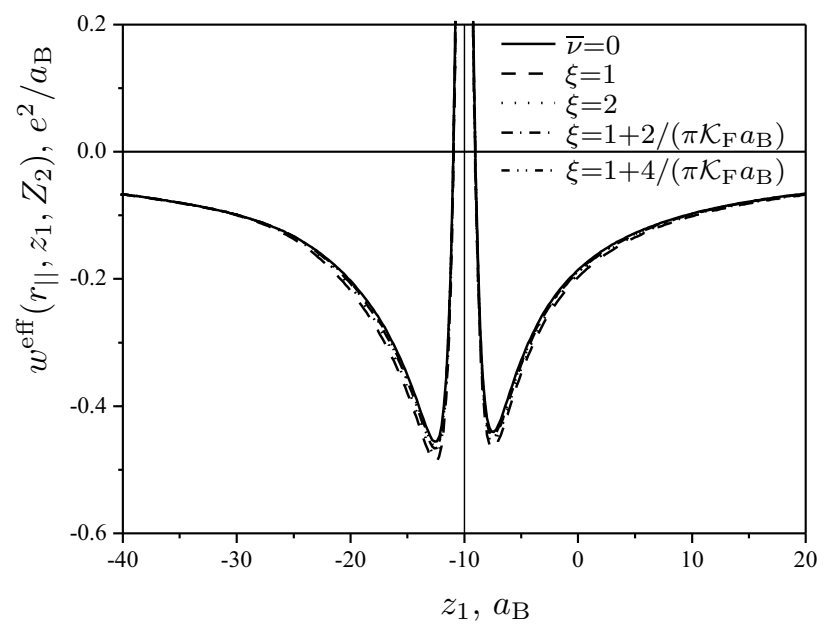

$\boldsymbol{d}\left(r_{\|}=0, Z_{2}=-10 a_{\mathrm{B}}\right)$

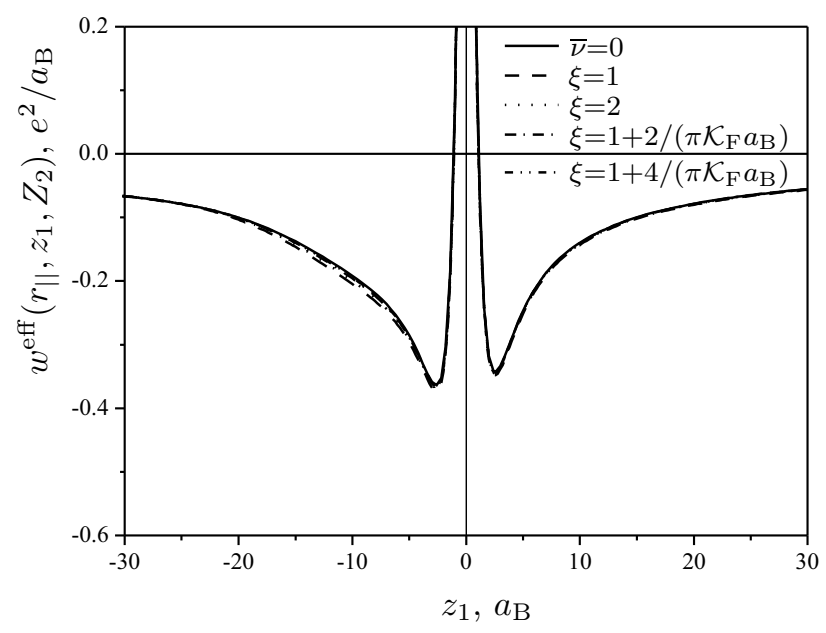

$f\left(r_{\|}=0, Z_{2}=0\right)$

Fig. 2. The effective potential of the electron-ion interaction as a function of the electron coordinate, which is normal to the metal/vacuum interface. 

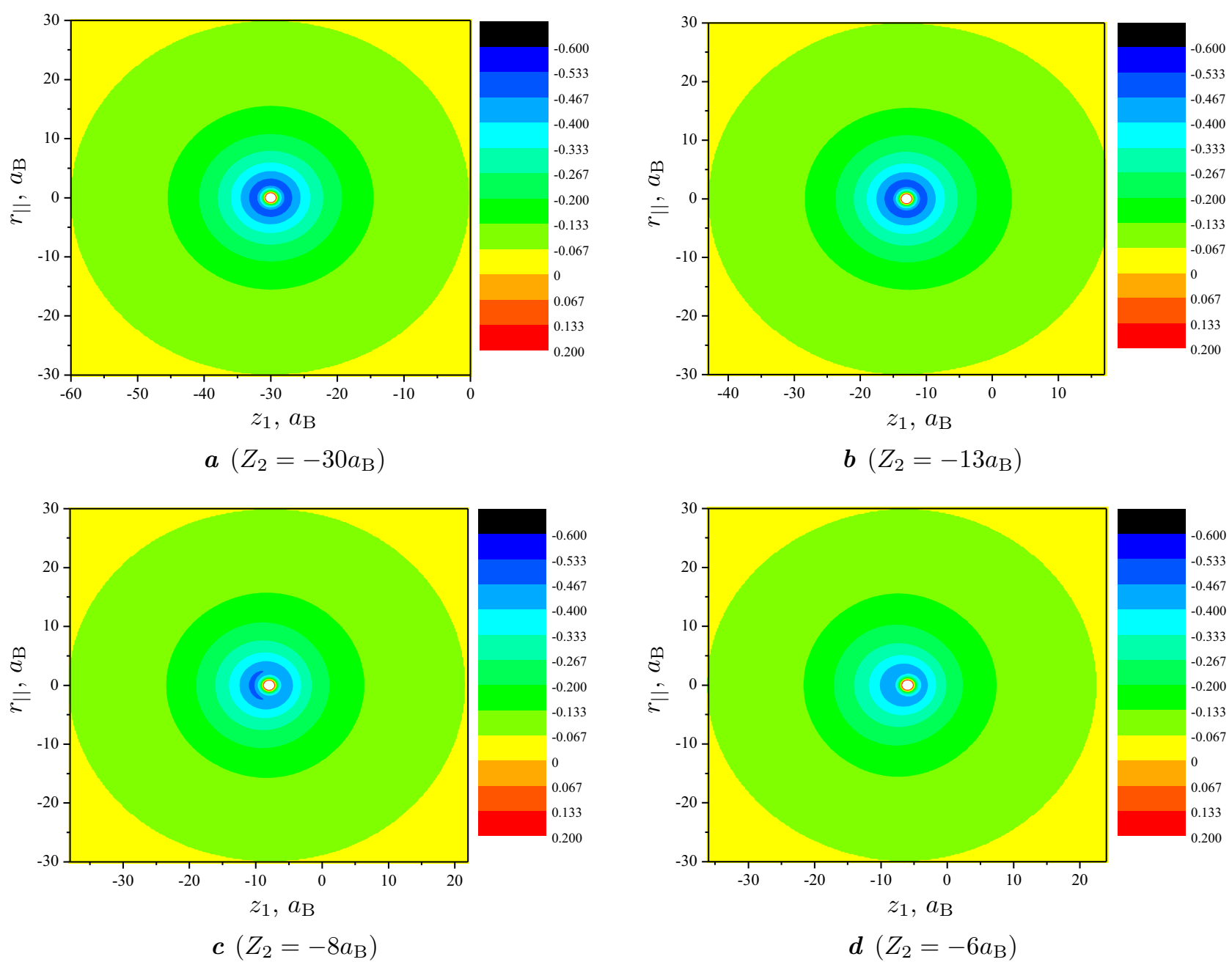

$\boldsymbol{c}\left(Z_{2}=-8 a_{\mathrm{B}}\right)$
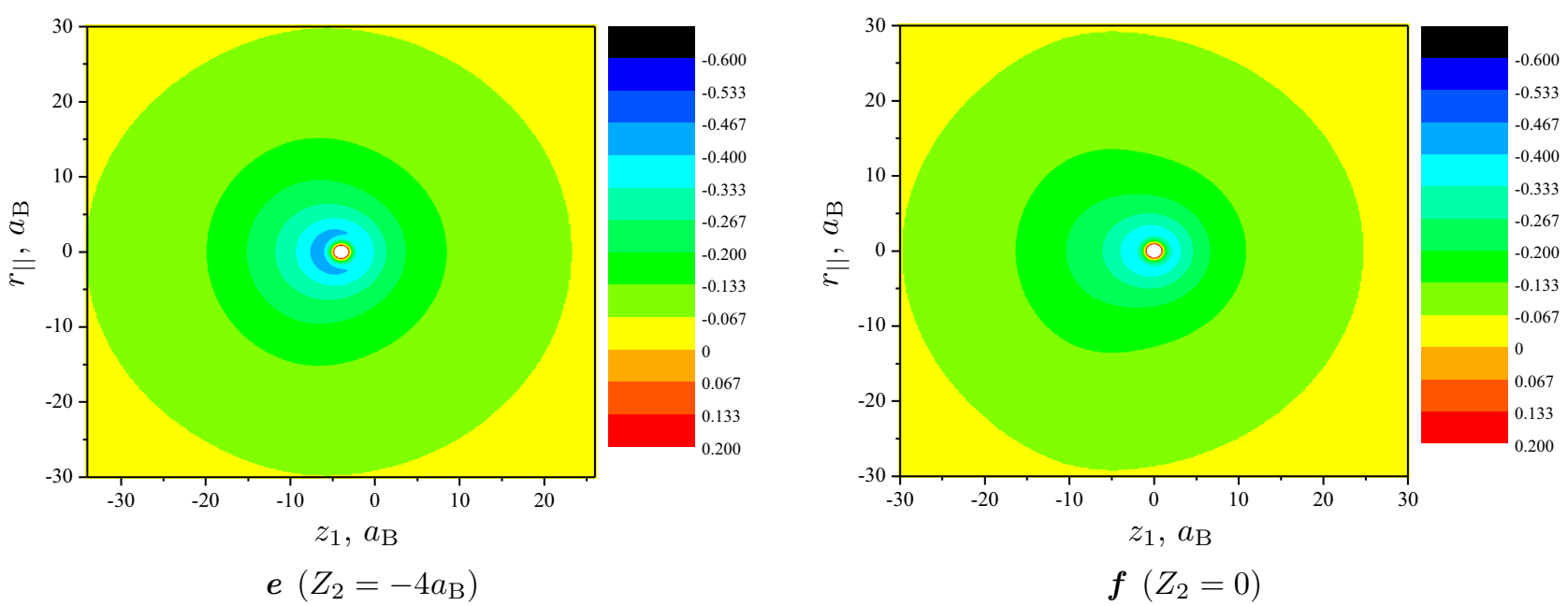

Fig. 3. The effective potential of the electron-ion interaction as a function of the electron coordinate, which is normal to the metal/vacuum interface, and the distance between electron and ion in the parallel plane to the metal/vacuum interface. 
[3] Kaim S. D. O mnogochastichnom podhode v teorii metallicheskoj poverhnovsti. Ukr. Fiz. Zhurn. 26 (8), 1351-1357 (1981), (in Russian).

[4] Kostrobij P.P., Markovych B. M. An effective potential of electron-electron interaction in semi-infinite jellium. Condensed Matter Physics. 9 (4), 747-756 (2006).

[5] Kostrobij P. P., Markovych B. M. Semi-infinite jellium: Thermodynamic potential, chemical potential, and surface energy. Phys. Rev. B. 92 (7), 075441 (2015).

[6] Kostrobij P. P., Markovych B. M. Semi-infinite jellium: Step potential model. Phys. Rev. B. 93 (15), 155401 (2016).

[7] Yakibchuk P. M. Calculation of the thermodynamical potential for the electron-ionic model of metal with nonlocal interactions. Condensed Matter Physics. 10, 179-187 (1997).

[8] Yakibchuk P. M., Shvec V. T. Modelni metodi u fizici metaliv. Lviv. nac. un-t im. Ivana Franka, L'viv (2012), (in Ukrainian).

[9] Gurskij Z. A., Krasko G. L. Modelnyj psevdopotencial i nekotorye atomnye svojstva shhelochnyh i shhelochnozemelnyh metallov. Doklady Akademii nauk SSSR. 197 (4), 810-813 (1971), (in Russian).

[10] Krasko G. L., Gurskij Z. A. Ob odnom modelnom psevdopotenciale. Pisma v JETF. 9, 596-601 (1969).

[11] Gradshtejn I. S., Ryzhik I. M. Tablicy integralov, summ, rjadov i proizvedenij. Nauka, Moscow (1971), (in Russian).

[12] Kostrobij P.P., Markovych B.M. Semi-infinite metal: thermodynamic potential and effective interionic pair potentials. AIP Conference Proceedings. 1198, 78-86 (2009).

[13] Mahan G. D. Many-particle physics. Plenum Press, New York (1990).

[14] Gorobchenko V.D., MaksimovE. G. The dielectric constant of an interacting electron gas. Sov. Phys. Usp. 23 (1), 35-58 (1980).

[15] Markovych B. M., Zadvorniak I. M. Effective potential of electron-electron interaction in the semiinfinite electron gas with regard for the local-field correction. Ukr. J. Phys. 59 (11), 1107-1113 (2014).

\title{
Дослідження ефективного потенціалу електрон-іонної взаємодії в напівобмеженому металі
}

\author{
Маркович Б. \\ Національний університет "Львівсъка політехніка", \\ вул. С. Бандери, 12, Львів, 79013, Україна
}

\begin{abstract}
Подано чисельні розрахунки ефективного потенціалу електрон-іоної взаємодії в напівобмеженому металі (калії) з урахуванням поправки на локальне поле у формі Хаббарда з використанням локального псевдопотенціалу Красько-Гурського. Досліджено вплив поверхні поділу "метал-вакуум" та апроксимації для поправки на локальне поле на поведінку ефективного потенціалу електрон-іонної взаємодії.
\end{abstract}

Ключові слова: ефективна електрон-іонна взаємодія, напівобмежений метал, поправка на локальне поле.

2000 MSC: $82 \mathrm{~B} 24$

УдК: 530.145

Mathematical Modeling and Computing, Vol.5, No. 2, pp. 184-192 (2018) 